\title{
The importance of genes and environment for ocular refraction and its determiners: a population based study among 20-45 year old twins
}

\author{
Niels Lyhne, Anne Katrin Sjølie, Kirsten Ohm Kyvik, Anders Green
}

\begin{abstract}
Aims-To estimate the heritability for ocular refraction and its determiners in a population based cohort of 20-45 years old twins.

Methods-114 twin pairs (53 monozygotic and 61 dizygotic) participated. Refraction was determined in cycloplegia and eye dimensions were measured with ultrasound. Educational length was assessed. The heritability was estimated employing aetiological model fitting. Evidence of gene-environment interaction was analysed. Correlations between intrapairwise differences in educational length and in refraction were evaluated.
\end{abstract}

Results-The heritability was between $\mathbf{0 . 8 9}$ and 0.94 (95\% CI: $0.82,0.96)$ for refraction, total refraction, axial length, and radius of corneal curvature. Phenotypic variation was mostly due to additive genetic effects. Refraction revealed evidence of geneenvironment interaction $(r=-0.29$ to $-0.32 ; p<0.05)$. The heritability for anterior chamber depth and lens thickness was between 0.88 and 0.94 (95\% CI: $0.81,0.96$ ) and dominant genetic effects were the most likely explanation. There was no correlation between age and intrapairwise differences in refraction. The dizygotic twins had significant larger intrapairwise differences in educational length $(p<0.05)$, but the differences were not correlated with differences in refraction.

Conclusions-The results indicate a high heritability for ocular refraction and its determiners and thus suggest that environmental impact on refraction is not significant. However, the epidemiological association between educational length (near work) and myopia, the evidence of increasing myopia prevalence within a few generations, and the theory of geneenvironment interaction imply that some individuals might be genetically liable to develop myopia if exposed to certain environmental factors.

(Br F Ophthalmol 2001;85:1470-1476)

Ophthalmology

Odense University

Hospital, Odense,

5000 C, Denmark

N Lyhne

A K Siølie

K O Kyvik

A Green

Correspondence to: Niels Lyhne

n_lyhne@hotmail.com

Accepted for publication 23 May 2001

The purpose of this study was to estimate the relative importance of genes and environment for ocular refraction and its determiners in a population based cohort of 20-45 years old twin pairs.

Several studies have addressed the issue of genetic and environmental impact on ocular refraction and its determiners. ${ }^{1-4}$ The association between myopia and educational length (that is, more education being associated with more near work) found in epidemiological studies $^{56}$ and evidence from family offspring studies of increasing myopia prevalence over a few generations in many countries, ${ }^{7-10}$ suggest a connection between the environment and ocular refraction. Yet, a high prevalence of myopia in certain environments, such as among university students, could be a result of natural selection and thus be genetically determined. ${ }^{1}$ Further, differences in both age and environment between generations could increase variation between parents and offspring and therefore family offspring studies cannot clearly distinguish between the importance of genes and environment. Finally, selection bias and lack of external validity could influence the conclusions of some studies.

Twin studies eliminate pairwise differences in age and can, under certain assumptions about the environment, account for genetic and environmental influence on biological variation. ${ }^{11}$ Previous twin studies have shown varying, but mostly high, heritability for ocular refraction and its determiners (refraction: 0.24 to 0.98 , the majority from 0.72 to 0.98 and determiners: 0.24 to 0.83 , the majority from 0.40 to 070$).{ }^{12-18}$ However, several had methodological flaws. Some were not population based. Others did not use cycloplegia when measuring refraction or merely used spectacle prescriptions. Age spans were wide and some studies included children and people more than 45-50 years of age in which refractive changes can be large within a few years. Furthermore, no studies adjusted the data for age and sex effects, and heritability estimates thus might be too low, owing to inflation of the dizygotic twin correlations. ${ }^{19}$. Finally, previous twin studies on ocular refraction used "classic" quantitative genetic methods. These methods cannot uncover dominant genetic effects (see notes at the end of the paper) or suggest which aetiological model best explains the data. ${ }^{11}$ The aim of the present study was to estimate the heritability of ocular refraction and its determiners, look for evidence of gene-environment interaction, and solve some of the described methodological problems.

\section{Materials and methods}

A total of 118 healthy (according to previously mailed questionnaire) same sex twin pairs between 20 and 45 years old were randomly recruited from the young part of the population based Danish Twin Register. ${ }^{20}$ Twenty two pairs had only their eyes examined, whereas 96 pairs also participated in other surveys. Eyes with 
pathology, previous eye surgery, steroid treatment for more than 1 month, clinically significant amblyopia ("two line rule" on Snellen board), or excessive myopia (myopia more than 6 dioptres and signs in the fundus) were excluded. This resulted in 114 twin pairs, in which each pair could contribute with a minimum one pair of "normal" same side eyes. These pairs participated in the heritability estimates.

Ocular refraction $(\mathrm{Rf}=$ spherical equivalentthat is, sphere + half the cylinder) was determined using an automated refractor (Canon RK-2) and cycloplegia (achieved 30 minutes after last of two drops given 10 minutes apart of cyclopentolate hydrochloride $1 \%$ ). Corneal radii of curvature were measured with an automated keratometer (Canon RK-2) and the values from the two principal meridians were
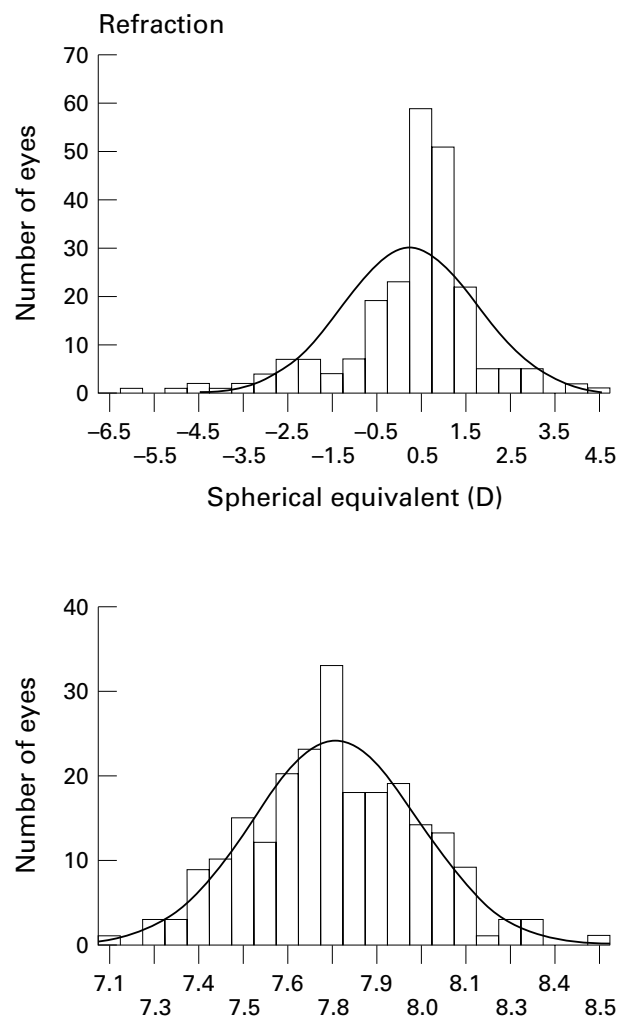

Mean radius of corneal curvature $(\mathrm{mm})$

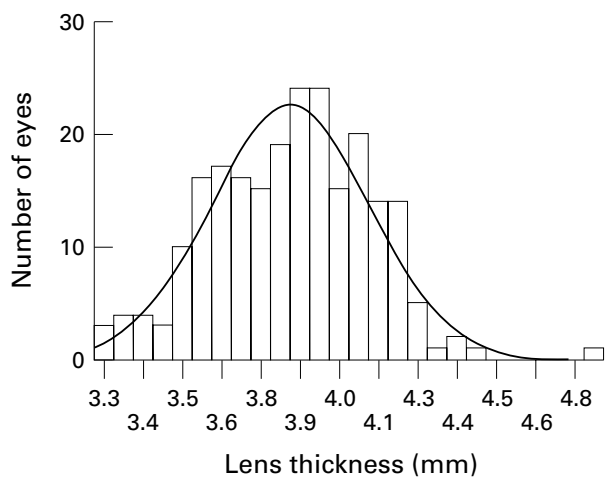

averaged. Anterior chamber depth, lens thickness, and axial length were measured with ultrasound (Teknar Ophthasonic Auto A Scan: velocity in vitreous $1532 \mathrm{~m} / \mathrm{s}$ and lens 1641 $\mathrm{m} / \mathrm{s}$ ). Additionally, refraction was transformed using the formula:

Rf-trans $=(R f-0.78) \times \mathrm{ABS}(\mathrm{Rf}-0.78)^{-0.5}$

(ABS $=$ absolute value $=$ numeric value $)$ to achieve a Gaussian distribution. ${ }^{21}$ Total refraction $\left(\mathrm{Rf}_{\mathrm{t}}\right)$ was calculated by $\mathrm{Rf}_{\mathrm{t}}=(1392 /$ axial length) - Rf). ${ }^{22}$ The twins were divided into the two zygosity groups (monozygotic and dizygotic) using nine microsatellite and RFLP markers (Hum VWA31/A(p9), D3S1358, FGA, D8S1179, D21S11, D18S51, D5S818, D13S317, and D7S820). Finally, data on educational length were collected from the twins
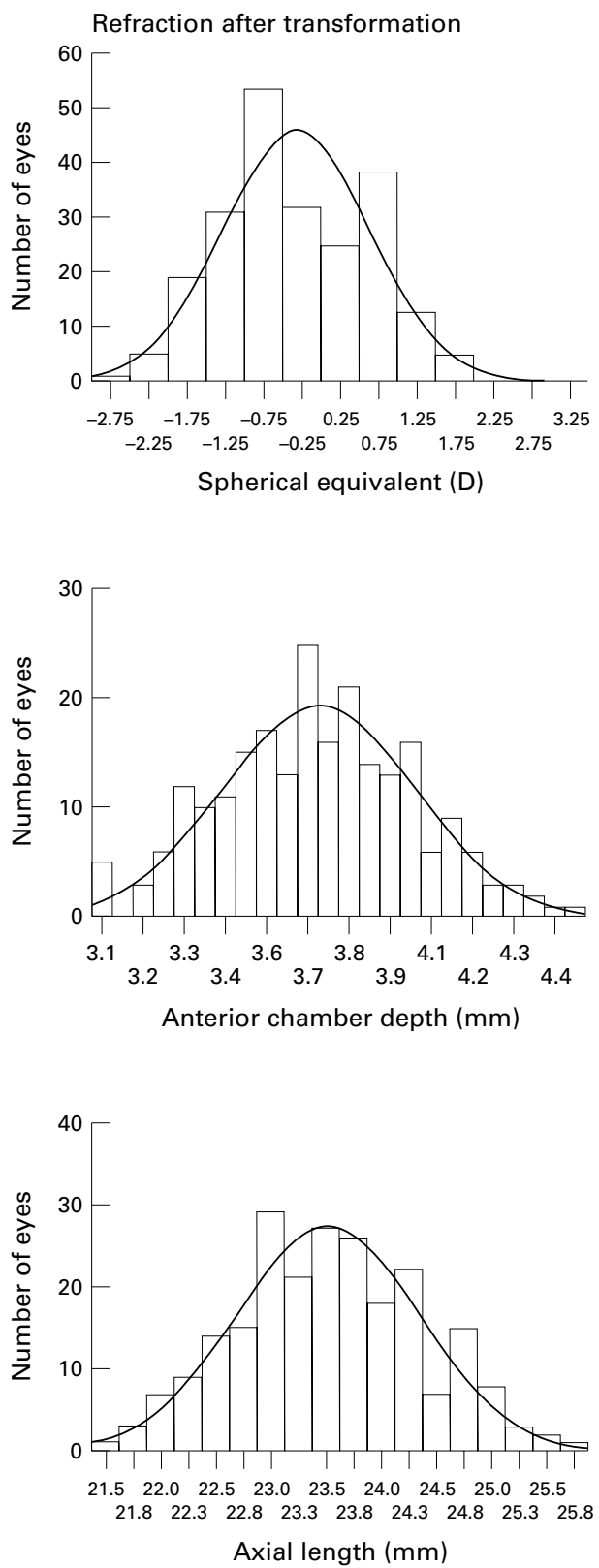

Figure 1 Histograms showing the distribution of ocular refraction and its determiners in right eyes. The Gaussian curves are based on the measured values. 
by means of a questionnaire. Educational length was the sum of years attending school (basic school and high school, between 7 and 12.5 years) and higher education (between 0 and actual number of years studying).

Age or sex dependent determiners of refraction were adjusted statistically using single and multiple linear regression and the residuals were used in the heritability estimates. ${ }^{19}$ Lastly, in each zygosity group, measurements with intrapairwise differences exceeding three standard deviations, compared with the mean intrapairwise difference in the group, were
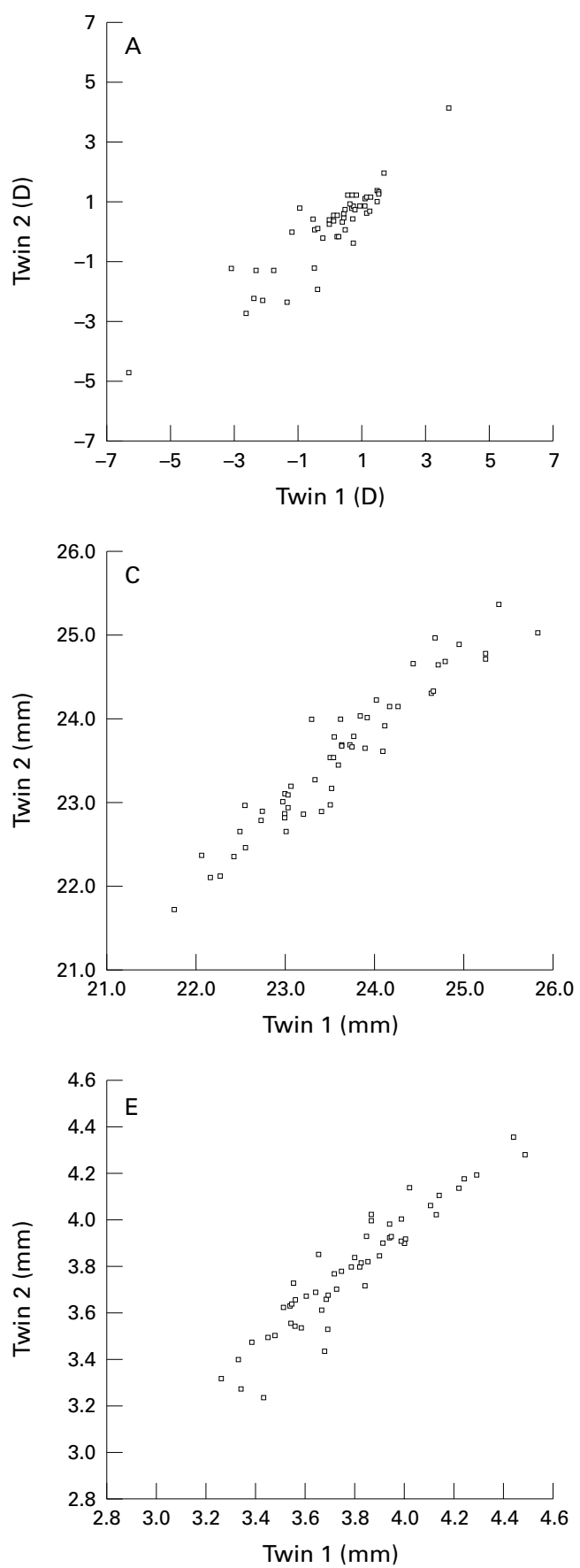

considered outliers and excluded from the heritability analysis.

The heritability was estimated by means of an aetiological model based on structural equations. ${ }^{1123}$ The model estimates the proportion of phenotypic variation due to additive and dominant genetic effects and to common and unique environmental effects, respectively. It assumes the same degree of common environment among monozygotic and dizygotic twin pairs and no gene-environment interaction (see notes for a definition of these terms).
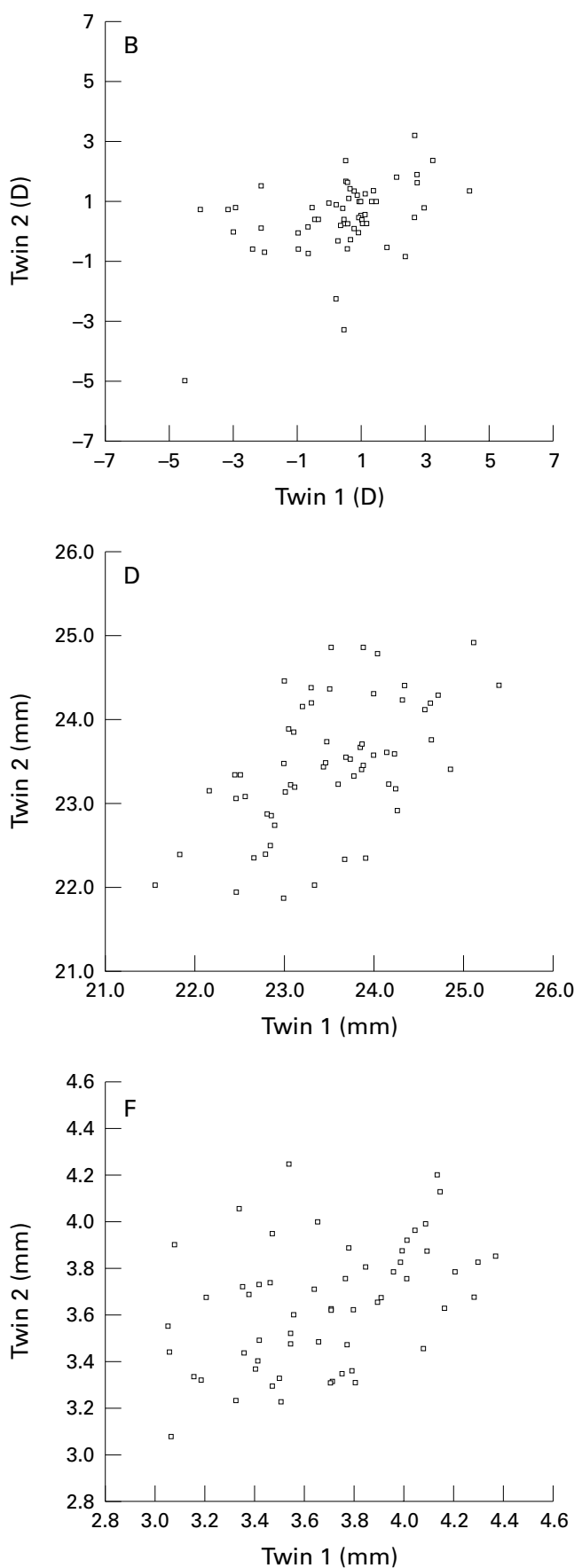

Figure 2 Intrapairwise correlation, Pearson's $r_{p}(95 \%$ CI) for refraction, axial length, and anterior chamber depth) in monozygotic (MZ) and dizygotic twins (DZ). Right eyes. Age and sex dependent determiners were adjusted before the heritability analysis. (A) MZ: refraction $r=0.91$ (95\% CI 0.85, 0.95); (B) DZ: refraction $r=0.44$ (95\% CI 0.21, 0.63 ); (C) MZ: axial length $r=0.95(95 \%$ CI 0.92, 0.97);(D) DZ: axial length $r=0.56(95 \%$ CI 0.36, 0.71); (E) MZ: anterior chamber depth $r=0.94$ (95\% CI 0.90, 0.97); (F) DZ: anterior chamber depth $r=0.43$ (95\% CI 0.20, 0.62). 
Evidence of gene-environment interaction was analysed by means of the monozygotic twin pairs. Among these pairs a statistically significant correlation between (1) the intrapairwise sum of a measured value, and (2) the absolute value of the intrapairwise difference is evidence of gene-environment interaction. The analysis does not permit a quantitative assessment of the interaction. ${ }^{24}$

\section{Results}

Of the 114 pairs included in the analysis 53 were monozygotic (23 males (median age 34.7 years, range 19.8-45.4 years) and 30 females (29.9 years, range $19.4-44.2$ years)) and 61 were dizygotic (27 males (median age 38.1 years, range 19.9-43.4 years) and 34 females (37.0 years, range $20.3-44.3$ years)).

Ocular refraction demonstrated the typical bimodal distribution with non-Gaussian crowding around emmetropia and a moderate accumulation in the myopic end of the scale. Approximately $25 \%$ of the people were myopic with a myopic spherical equivalent $\geqslant 0.25 \mathrm{D}$. The refractive determiners had a Gaussian distribution. The distribution of refraction and its determiners in the right eyes are seen in Figure 1, in conjunction with the transformed refraction data. The left eyes demonstrated the same pattern.
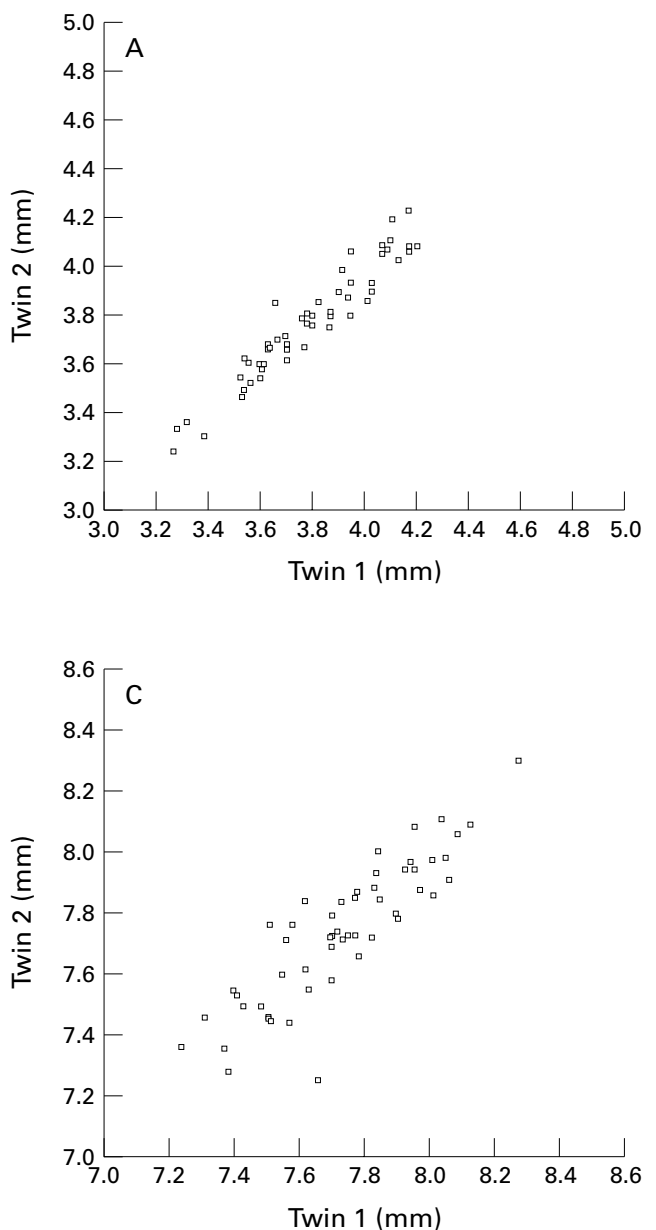

Figures 2 and 3 are graphical representations of the intrapairwise correlation of right eye refraction and its determiners in monozygotic and dizygotic twins. Age or sex dependent data are not adjusted in these figures and refraction is not transformed. The left eyes had similar correlations.

Regression analysis revealed that total refraction, axial length, and radius of corneal curvature were sex dependent $(p<0.01)$, while lens thickness was age dependent $(\mathrm{p}<0.01)$ and anterior chamber depth was both age and sex dependent $(\mathrm{p}<0.01)$. These values were adjusted before the heritability analysis. ${ }^{19}$

Finally, outlier measurements according to the outlined "three standard deviation rule" for intrapairwise differences in each zygosity group were identified and excluded: left refraction in one monozygotic pair, right total refraction in two monozygotic pairs, left total refraction in one monozygotic and one dizygotic pair, left axial length in one monozygotic and one dizygotic pair, left lens thickness in one monozygotic pair and right and left corneal curvature in to different monozygotic pairs.

Table 1 is an example of model fitting results, explaining the strategy for choosing the
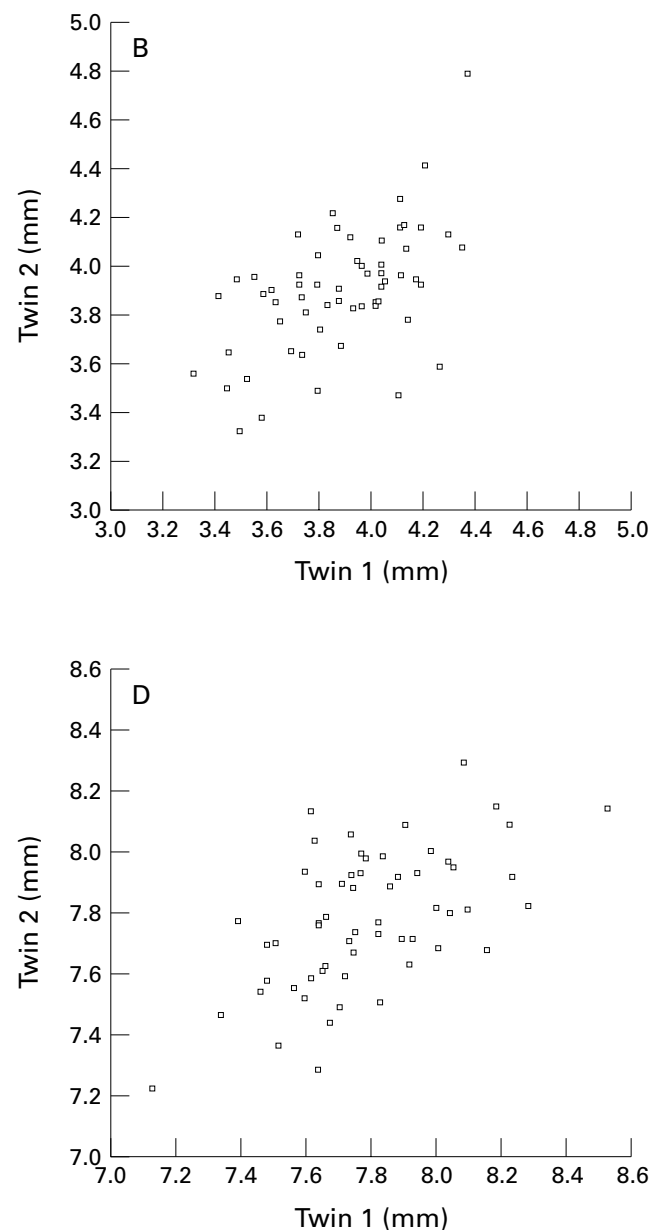

Figure 3 Intrapairwise correlation, Pearson's $r_{p}(95 \% C I)$ for lens thickness $(A, B)$ and mean radius of corneal curvature (Rad cc) $(C, D)$ in monozygotic $(M Z)$ and dizygotic twins $(D Z)$. Right eyes. Age and sex dependent determiners were adjusted before the heritability analysis. (A) MZ: lens thickness $r=0.95(95 \%$ CI 0.92, 0.97); (B) DZ: lens thickness $=0.54$ (95\% CI 0.33, 0.70); (C) MZ: Radcc $r=0.90$ (95\% CI 0.83, 0.94); (D) DZ: Radcc $r=0.57$ (95\% CI 0.37, 0.72) 
best fitting aetiological model for ocular refraction. The data are transformed to Gaussian distribution. Table 2 shows the results of the heritability analysis for ocular refraction and its determiners. The heritability was estimated to be between 0.89 and 0.94 (95\% CI: 0.82, 0.96) for refraction, total refraction, axial length, and radius of corneal curvature. Phenotypic variation was mostly due to additive genetic effects.

Pairs with one or both twins being myopic exhibited the largest intrapair differences in refraction. The differences were most pronounced in the dizygotic pairs. These pairs did not meet the basic assumptions of the aetiological model analysis: A Gaussian distribution and equal variances between zygosity groups. A separate analysis including these pairs was thus not permissible.

Anterior chamber depth and lens thickness had an estimated heritability between 0.88 and
0.94 (95 \% CI: 0.81, 0.96), and genetic dominance was the most likely explanation of phenotypic variation according to the aetiological model, though a combination with additive genetic effects was statistically plausible for the lens thickness.

Signs of gene-environment interaction in ocular refraction were analysed by means of the monozygotic pairs. Figure 4 illustrates this analysis. The analysis provided evidence of gene-environment interaction $(r=-0.29$ to $-0.32 ; \mathrm{p}<0.05$ ), although a quantitative assessment of the interaction was not possible.

There was no statistically significant correlation between age and intrapairwise differences in refraction in either zygosity group. Finally, refraction was negatively correlated with educational length $(r=-0.33 ; \mathrm{p}<0.01)$, and showed more myopia among people with more education (Fig 5). The median intrapairwise difference in educational length was 0.0 years

Table 1 Parameter estimation using aetiological model fitting on ocular refraction data after transformation to Gaussian distribution. Best fitting model in this case is the "AE model" (Additive genetic and unique Environmental effects), indicated in bold. (Abbreviations are explained in the footnote)

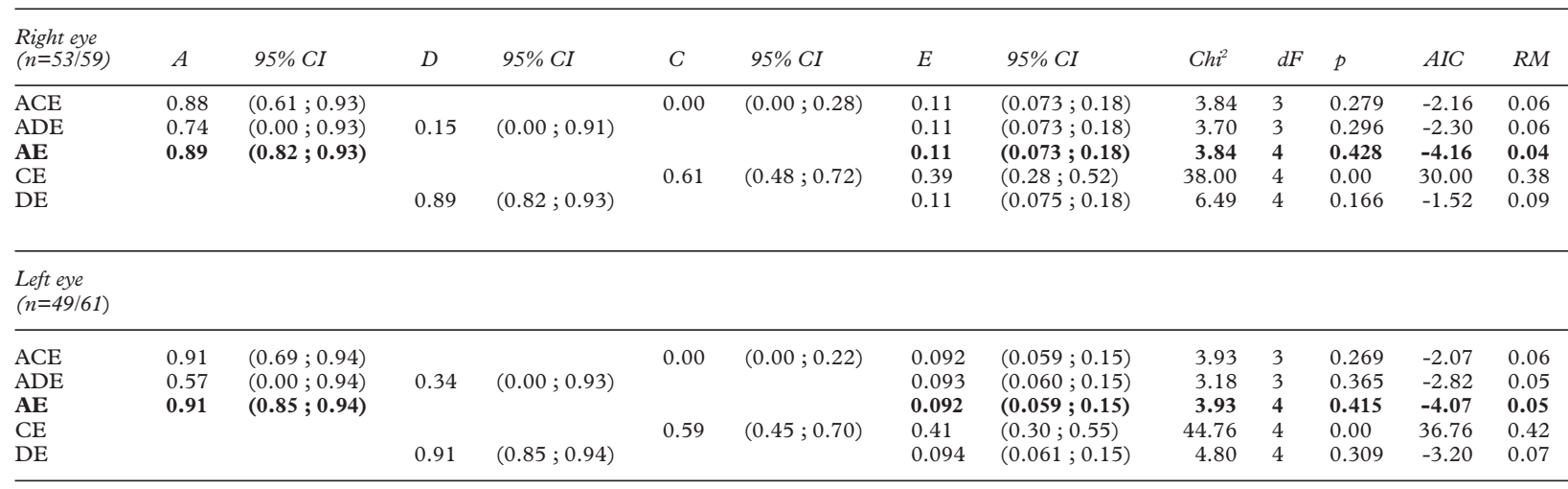

$\mathrm{N}=$ number of $\mathrm{MZ} / \mathrm{DZ}$ pairs.

The numbers differ from the total number of pairs because of the exclusion criteria and outliers, as explained in the text.

Estimated parameters:

$\mathrm{A}=$ proportion of phenotypic variation because of additive genetic effects.

$\mathrm{D}=$ proportion of phenotypic variation because of dominant genetic effects

$\mathrm{C}=$ proportion of phenotypic variation because of common environmental effects.

$\mathrm{E}=$ proportion of phenotypic variation because of unique environmental effects.

$95 \% \mathrm{CI}=95 \%$ confidence limits of estimate.

Goodness of fit test:

$\chi^{2}=$ chi square.

$\mathrm{dF}=$ degrees of freedom.

$\mathrm{p}=$ level of significance, should be non-significant.

AIC = "Akaikes test value", should be low and preferably negative.

$\mathrm{RM}=$ "RMSEA value," should be low ( $<0.1$ for a "good fit" and $<0.05$ for a "very good fit").

Table 2 Results of heritability analysis for ocular refraction and its determiners based on aetiological model fitting. Parameter estimate (95\% confidence interval of estimate)

\begin{tabular}{|c|c|c|c|c|c|}
\hline & Best fitting model & A: Additive genetic effects & D: Dominant genetic effects & $\begin{array}{l}\text { E: Unique environmental } \\
\text { effects }\end{array}$ & $N$ \\
\hline Refraction $_{\text {Right }}$ & $\mathrm{AE}$ & $0.91(0.86 ; 0.94)$ & & $0.09(0.06 ; 0.14)$ & $53 / 59$ \\
\hline Refraction $_{\text {Left }}$ & $\mathrm{AE}$ & $0.91(0.86 ; 0.94)$ & & $0.09(0.06 ; 0.14)$ & $49 / 61$ \\
\hline Refraction -trans $_{\text {Right }}$ & $\mathrm{AE}$ & $0.89(0.82 ; 0.93)$ & & $0.11(0.07 ; 0.18)$ & $53 / 59$ \\
\hline Refraction -trans ${ }_{\text {Left }}$ & $\mathrm{AE}$ & $0.91(0.85 ; 0.94)$ & & $0.09(0.06 ; 0.15)$ & $49 / 61$ \\
\hline Total refraction ${ }_{\text {Right }}$ & $\mathrm{AE}$ & $0.94(0.90 ; 0.96)$ & & $0.06(0.04 ; 0.10)$ & $51 / 59$ \\
\hline Total refraction & $\mathrm{AE}$ & $0.93(0.89 ; 0.96)$ & & $0.07(0.05 ; 0.11)$ & $49 / 60$ \\
\hline Axial length ${ }_{\text {Right }}$ & $\mathrm{AE}$ & $0.94(0.91 ; 0.96)$ & & $0.06(0.04 ; 0.09)$ & $53 / 59$ \\
\hline Axial length & $\mathrm{AE}$ & $0.94(0.90 ; 0.96)$ & & $0.06(0.04 ; 0.10)$ & $49 / 60$ \\
\hline $\mathrm{ACD}_{\text {Right }}$ & $\mathrm{DE}$ & & $0.94(0.90 ; 0.96)$ & $0.06(0.04 ; 0.10)$ & $53 / 59$ \\
\hline $\mathrm{ACD}_{\text {Left }}$ & $\mathrm{DE}$ & & $0.88(0.81 ; 0.92)$ & $0.12(0.08 ; 0.19)$ & $50 / 61$ \\
\hline Lens thickness ${ }_{\text {Right }}$ & $\mathrm{DE}$ & & $0.93(0.89 ; 0.96)$ & $0.07(0.05 ; 0.11)$ & $53 / 59$ \\
\hline Lens thickness ${ }_{\text {Left }}$ & $\mathrm{DE}$ & & $0.90(0.85 ; 0.94)$ & $0.10(0.06 ; 0.16)$ & $49 / 61$ \\
\hline Radcc $_{\text {Right }}$ & $\mathrm{AE}$ & $0.90(0.84 ; 0.93)$ & & $0.10(0.07 ; 0.16)$ & $52 / 59$ \\
\hline Radcc $_{\text {Left }}$ & $\mathrm{AE}$ & $0.92(0.87 ; 0.95)$ & & $0.08(0.05 ; 0.13)$ & $49 / 61$ \\
\hline
\end{tabular}

Refraction -trans = refraction transformed to Gaussian distribution, ACD = anterior chamber depth and Radcc = mean radius of corneal curvature.

Estimated parameters:

$\mathrm{A}=$ proportion of phenotypic variation because of additive genetic effects.

$\mathrm{D}=$ proportion of phenotypic variation because of dominant genetic effects.

$\mathrm{E}=$ proportion of phenotypic variation because of unique environmental effects.

$\mathrm{N}=$ number of $\mathrm{MZ} / \mathrm{DZ}$ pairs. 

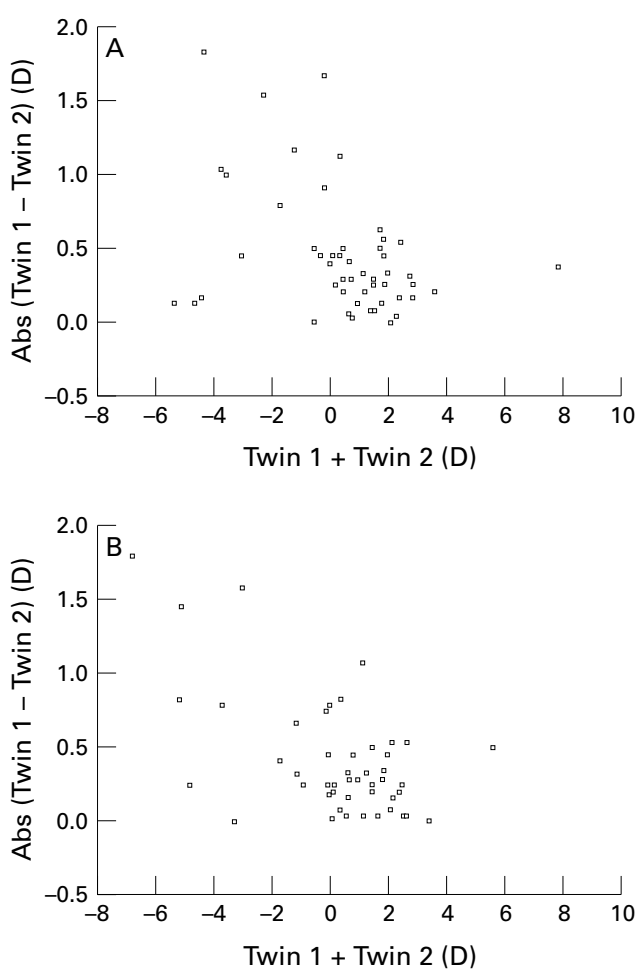

Figure 4 Analysis of gene-environment interaction for ocular refraction. Monozygotic twins. (A) Right eye, $r=$ $-0.32, p<0.05, n=52$ (Spearman rank correlation). (B) Left eye, $r=-0.29, p<0.05, n=49$ (Spearman rank correlation). Abs = absolute value.

(0.0-5.5 years) in the monozygotic pairs and 1.0 year $(0.0-8.0$ years $)$ in the dizygotic pairs. This difference between the zygosity groups was statistically significant $(\mathrm{p}<0.05)$, but the intrapairwise differences in educational length were not statistically significantly correlated with intrapairwise differences in refraction in either zygosity group. Only 50 monozygotic and 51 dizygotic pairs gave information about the length of their education.

\section{Discussion}

The present and other twin studies indicate a high heritability for ocular refraction and its determiners and do not suggest environmental changes could have a significant impact on refraction. However, the established association between educational length (near work) and myopia, the epidemiological evidence of increasing myopia prevalence within a few generations,

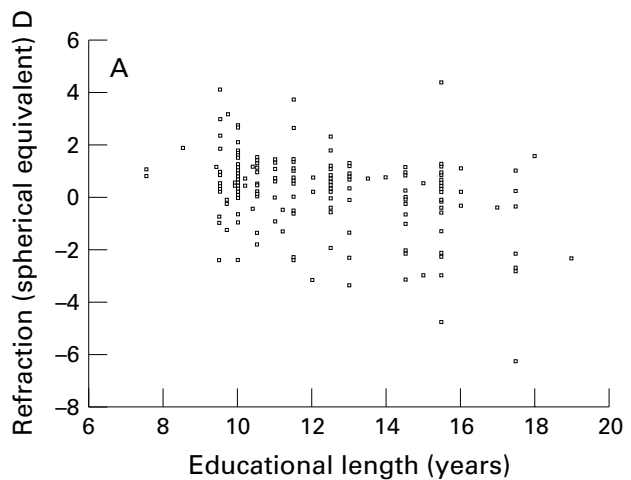

and the theory of gene-environment interaction suggest that intervention might be beneficial among individuals genetically liable to develop myopia due to near work. This could have significant clinical implications in a high risk environment where large numbers of individuals at risk may be exposed, as is presumably the case in certain Asian cities. This study provided qualitative evidence of gene-environment interaction for ocular refraction, suggesting that genetically liable individuals might develop myopia if exposed to certain environmental factors such as near work. However, the employed aetiological model, like the "classic" quantitative method, has the assumption of no such interaction. A quantitative estimation of geneenvironment interaction for ocular refraction would require modifications of the model, a very large sample of twins and, most importantly, reliable information about the relevant environmental factors (early childhood near work exposure and studying habits) encountered during their earlier life..$^{1125}$ This was outside the range of the present survey, as the twins were between 20 and 45 years old. Recall bias would probably flaw the information from the oldest twins and therefore no attempt was made to collect such information.

The phenotypic variation in lens thickness and anterior chamber depth was mostly due to genetic dominance. This finding differs from previous studies, which could not evaluate dominant genetic effects. The suggested importance of genetic dominance implies that these refractive determiners have experienced significant natural selection. Still, this finding does not exclude additive genetic effects as a supplementary source of variation in these refractive determiners, but estimation of three parameters requires a very large sample of twins to yield enough statistical power.

Twin studies are based on an important assumption concerning the environment: the same degree of common environment among both monozygotic and dizygotic pairs. If this is not true, a greater similarity between monozygotic pairs could be attributed to more similar environments. The larger intrapairwise differences in educational length among the dizygotic twins indicate a violation of this equal environment assumption, but the difference was modest and therefore probably did not

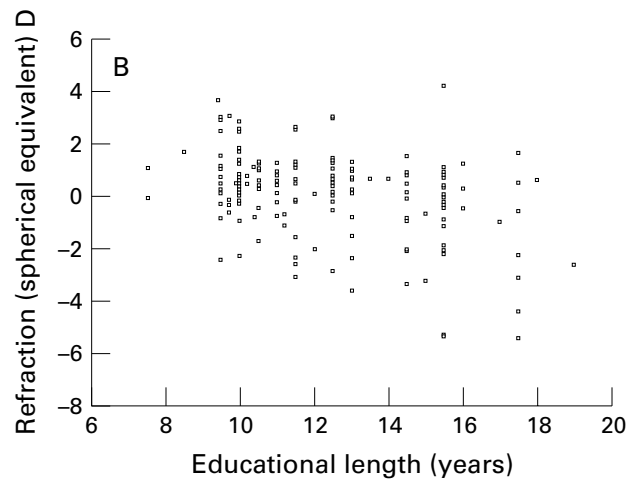

Figure 5 Refraction versus educational length: only pairs were both twins contributing information. (A) Right eye, $r=$ $-0.33, p<0.01$. (B) Left eye, $r=-0.34, p<0.01$ ). 
influence the heritability estimates significantly. The finding emphasises, in conjunction with the gene-environment interaction issue, that the heritability estimates from twin studies should be considered upper limits. It should also be emphasised that "educational length" is a crude measure of environmental factors. However, better data were not obtainable as described above.

By excluding measurements when intrapairwise differences were more than three standard deviations compared with the zygosity group mean intrapairwise difference, a few outlier pairs did not have an otherwise significant impact on the heritability estimates. A choice of a more rigorous value of two standard deviations would have excluded some dizygotic pairs with comparatively large intrapairwise differences and decreased the heritability estimates because of a relative inflation the dizygotic correlations. We did not find this justified.

The common environment presumably had no statistically significant effect on the phenotypic variation according to the aetiological modelling. This finding does not exclude common environmental influences on ocular refraction and its determiners, as a very large number of twin pairs is necessary to estimate this parameter. The estimate could be improved if other family members like parents and siblings were included, ${ }^{26}$ but this was outside the scope of the present study.

Any intervention against development of myopia among genetically liable individuals would require knowledge about when, under what circumstances, and against what the intervention should be directed. Previous trials have resulted in few significant results or have been cumbersome for the individuals. ${ }^{27-30}$ Further, it can be difficult to identify people at risk of developing myopia. As genetic factors seem important in ocular refraction and myopia, the mapping of the human genome might make screening methods available to identify these individuals. However, screening would call for an economical, safe, and simple treatment of developing myopia, considering its benign course in most cases.

Both corneal astigmatism and total astigmatism were not considered separately in this paper. The subject will be analysed in a later paper.

\section{Notes}

Heritability: The proportion of biological variation caused by genetic variation.

Gene-environment interaction: The environment has a differential impact on an individual's phenotype because of genotype, or a genotype may be expressed differently in some environments than in others.

Additive genetic effects: The sum of genetic effects taken singly and added over loci.

Dominant genetic effects: Genetic effects as a result of interaction between alleles on the same locus. Results in a heterozygote, which is not intermediate between individuals who are homozygous for two alleles on a certain locus.
Common environment effects: Environmental effects shared by individuals reared together and affecting them in the same way.

Unique environmental effects: Environmental effects affecting individuals reared together, either shared but affecting them differently, or non-shared. Includes variation in measurements.

1 Goldschmidt E. On the etiology of myopia. An epidemioogical study. Acta Ophthalmol Copenh 1968; (suppl 98): $122-7$.

2 Angle J, Wissmann DA. The epidemiology of myopia. Am $\mathcal{F}$ Epidemiol 1980;111:220-8.

3 Mohan M, Pakrasi S, Garg SP. The role of environmental factors and hereditary predisposition in the causation of low myopia. Acta Ophthalmol Suppl 1988;185:54-7.

4 Kinge B, Midelfart A, Jacobsen G, et al. The influence of near-work on development of myopia among university students. A three-year longitudinal study among engineering students in Norway. Acta Ophthalmol Scand 2000;78:26-9.

Teasdale TW, Goldschmidt E. Myopia and its relationship to education, intelligence and height. Preliminary results from an on-going study of Danish draftees. Acta Ophthalfrom an on-going study of

6 Fledelius HC. Myopia prevalence in Scandinavia. A survey, with emphasis on factors of relevance for epidemiological refraction studies in general. Acta Ophthalmol Suppl 1988;185:44-50

7 Sorsby A, Leary GA, Fraser GR. Family studies on ocular refraction and its components. F Med Genet 1966;3:269-73.

8 Alsbirk PH. Refraction in adult West Greenland Eskimos: a population study of spherical refractive errors, including oculometric and familial correlations. Acta Ophthalmol Scand 1979;57:84-95.

9 Johnson GJ, Matthews A, Perkins ES. Survey of ophthalmic conditions in a Labrador community. I. Refractive errors. Br f Ophthalmol 1979;63:440-8.

10 The Framingham Offspring Eye Study Group. Familial aggregation and prevalence of myopia in the Framingham Offspring Eye Study. Arch Ophthalmol 1996;114:326-32.

11 Neale MC, Cardon LR. Methodology for genetic studies of twins and families. Dordrecht, Boston, London: Kluwer twins and families. Dor.

12 Sorsby A, Fraser GR. Statistical note on the components of ocular refraction in twins. F Med Genet 1964;47:47-9. Chinese Med F 1981;94:51-5.

3 Chu R, Kuo P, Wang Y, et al. Myopia incidence among twins and its genetic law. Acta XXIV International Congress of Ophthalmology. San Francisco, 1982:84-6.

14 Lin LL, Chen CJ. A twin study on myopia in Chinese school children. Acta Ophthalmol Suppl 1988;185:51-3.

15 Teikari J, O'Donnell JJ, Kaprio J, et al. Genetic and environmental effects on oculometric traits. Optom Vis $S_{c i}$ 1989;66:594-9

16 Teikari J, Koskenvuo M, Kaprio J, et al. Study of geneenvironment effects on development of hyperopia: a study of 191 adult twin pairs from the Finnish Twin Cohort Study. 191 adult twin pairs from the Finnish Twin C.

17 Valluri S, Minkovitz JB, Budak K, et al. Comparative corneal topography and refractive variables in monozygotic and topography and refractive variables in monozygotic

dizygotic twins. Am f Ophthalmol 1999;127:158-63.
8 McGue M, Bouchard TJ. Adjustment of twin data for the effects of age and sex. Behav Genet 1984;14:325-43.

19 Kyvik KO, Christensen K, Skytthe A, et al. The Danish twin register. Dan Med Bull 1996;43:467-70.

20 Blackie CA, Harris WF. Refraction and keratometry: departures from and transformations toward multivariate normality. Optom Vis Sci 1997;74:452-8.

21 Van Alphen GWHM. On emmetropia and ametropia. $O p h-$ thalmologica 1961;142:1-92.

22 Neale MC, Boker SM, Xie G, et al. Mx statistical modeling. Computer Program (4.1), 1999.

23 Martin N. Gene-environment interaction and twin studies. In: Spector TD, Snieder H, MacGregor AJ, eds. Advances in twin and sib-pair analysis. London: Greenwich Medical Media, 2000:143-50.

24 Chen CJ, Cohen BH, Diamond EL. Genetic and environmental effects on the development of myopia in Chinese mental effects on the development of myopia in Chinese
twin children. Ophthalmic Paediatr Genet 1985;6:353-9.

25 Hopper JL. Why "common environment effects" are so uncommon in the literature. In:Spector TD, ed. Advances in twin and sib-pair analysis. London: Greenwich Medical Media, 2000:152-63.

26 Schwartz JT. A monozygotic cotwin control study of a treatment for myopia. Acta Genet Med Gemellol Roma 1976;25: 133-6.

27 Schwartz JT. Results of a monozygotic cotwin control study on a treatment for myopia. Prog Clin Biol Res 1981;69(Pt C) : $249-58$

28 Jensen H. Myopia progression in young school children. A prospective study of myopia progression and the effect of a trial with bifocal lenses and beta blocker eye drops. Acta Ophthalmol Scand 1991;Suppl:1-79.

29 Jensen H. Myopia in teenagers. An eight-year follow-up study on myopia progression and risk factors. Acta Ophthalmol Scand 1995;73:389-93. 